\title{
Pedagogical Shifts in Medical Health Education
}

\author{
Alberto J. de Armendi ${ }^{1}$, Edmund A. Marek ${ }^{2}$ \\ ${ }^{1}$ Department of Anesthesiology, Oklahoma University Health Sciences Center, Oklahoma City, USA \\ ${ }^{2}$ Jeannine Rainbolt College of Education, University of Oklahoma, Norman, USA \\ Email: alberto-dearmendi@ouhsc.edu, eamarek@ou.edu
}

Received April 24 $4^{\text {th }}$, 2013; revised May $25^{\text {th }}$, 2013; accepted June $2^{\text {nd }}, 2013$

\begin{abstract}
Copyright (c) 2013 Alberto J. de Armendi, Edmund A. Marek. This is an open access article distributed under the Creative Commons Attribution License, which permits unrestricted use, distribution, and reproduction in any medium, provided the original work is properly cited.
\end{abstract}

\begin{abstract}
The medical education system has evolved over time and undergone a radical transformation in the past few decades. With advancements in disease treatments, emergence of new specialties and highly competitive practicing environment, the focus has shifted from gaining knowledge to acquiring degrees. This paper presents 1) where we have been, 2) problems that we have faced, 3) our present status and 4) where we need to be in the future.
\end{abstract}

Keywords: Medical Health Education

\section{History}

When Abraham Flexner was a research scholar at the Carnegie Foundation for the Advancement of Teaching, he described medical education at the turn of last century as, "students paying a fee for a diploma for their mediocre medical education”. The Flexner Report (Flexner, 1910) transformed medical school education to strictly adhere to protocols of mainstream science teaching (basic sciences, research, and clinical care) (Cooke et al., 2006). Since then, multiple reports have criticized the rote lecture memorization and the regurgitation of scientific knowledge in medical schools. Does passing organic chemistry with good grades guarantee development of good doctors? Cooke and others (Cooke et al., 2006) disagree and instead emphasize the need for focusing on practical and professional skills that allow for the maturation of reasoning and the development of professional values and compassion. As Cooke points out, it is much easier to teach basic sciences than to teach inter-personal professional teamwork, self-evaluation, and self-improvement. The single mission of academic medicine is to improve the health of the population (Ramsey \& Miller, 2009). Instead, healthcare costs have escalated, and waste persists with major medical errors and patient safety concerns. In 2011, Orszag, as Director of the USA Congressional Budget Office, reported to the US Senate Budget Committee that more than \$2 trillion is spent on medical care with $\$ 700$ billion failing to improve health care when compared to other countries that spend less. Medical and health education focuses need to change if we are going to control the continuous rising cost of health care.

McGlynn and colleagues, researchers at the Rand Corporation, noted that "In America, there is no guarantee that any individual will receive high-quality care for any particular health problem. The healthcare industry is plagued with overutilization of services, underutilization of services, and errors in healthcare practice” (McFlynn et al., 2003). The research also showed that Americans receive evidence-based healthcare only $50 \%$ of the time. Deyo and others (Deyo, 1991) (at the Univer- sity of Washington showed in their interdisciplinary study, Back Pain Patient Assessment Team, that what physicians thought worked well for treating back pain, in reality did not. Given the status of our healthcare system, what is the present condition of medical and health education (MHE)? Do MHE instructors continue to deliver large residential, conference lectures to health care students in conventional settings? Innovations began in the early 1990s at Harvard University Medical School. Harvard's medical education connected the classroomlearned knowledge to immediate clinical applicability of the same subject (connecting the basic sciences and the clinical rotations). A new era had begun. The relationship of classroom learning and immediate applicability was the buzzword of the time.

In the early 2000s, problems paying medical schools' academic faculty resulted in faculty seeing as many patients in as short a period of time as possible. This practice was to the detriment of the faculty becoming advisors, role models, and mentors for the new generation of medical students. The loss included quality teaching. In addition, physicians' egocentricities did not allow for team building and collaboration with other health care workers. Intimidation, nested in hidden curriculum, led to abuse and unprofessional behavior toward subordinates creating an atmosphere of fear and not learning.

Aware of deficiencies in MHE, the Graduate Medical Education recognized the importance of self-improvement and system awareness (ACGME, 2006). In 2006, the Accreditation Council for Graduate Medical Education set requirements for integrating six general competencies into the medical school curricula: 1) medical knowledge, 2) patient care, 3) professionalism, 4) interpersonal and communication skills, 5) system-based practice, and 6) practice-based learning and improvement. MHE continues to struggle with how to teach and evaluate these competencies.

Medical and health educators are also compelled to teach Comparative Effectiveness Research (CER), which offers quality, safety at lower cost. In other words, what teaching practices 
and learning theories work best at the greatest cost-to-benefit ratio. The Institute of Medicine (IOM) reported the need to have a federal CER organizational infrastructure roadmap to set future CER priorities and to teach CER to every student in clinical practice. At this time, over 100 priority study topics are on the website out of over 1250 nominated research proposals (IOM, 2009). In addition, Crew Resource Management (CRM) has been shown to reduce medical errors. The future is to teach interactive dynamics, patient safety, care delivery improvements, communication, and teamwork skills in these settings. In order for this to occur, we need the convergence of curriculum reform interests from among all major national stakeholders (the Association of American Medical Colleges, The Institute of Healthcare Improvement, the American Medical Student Association, the Agency for Healthcare Research and Quality and the Lucian Leape Institute), as well as, the international academic community.

\section{Present Educational Issues}

At present, efforts are underway nationally and internationally at health sciences' medical centers and at conferences to incorporate simulation technology to educate our health care force. Among others, examples include: computer-based virtual reality simulators, high fidelity and static mannequins, plastic models, live animals, professional patient-actors, inert animal products, and human cadavers. Gurusamy et al. (Gurusamy et al., 2008) evaluated randomized controlled trials and concluded that virtual reality training can supplement and/or replace conventional laparoscopic training in surgical trainees with limited or no laparoscopic experience. Ma et al. (Ma et al., 2011) in a systematic review and meta-analysis of 20 studies on central venous line catheterization, concluded that simulation-based education was associated with significant improvement and benefits in a) learner outcomes (performance on simulators, knowledge, and confidence) and b) selected patient clinical outcomes (fewer needle attempts and pneumothorax). Cook et al. (Cook et al., 2011) in a systematic review and meta-analysis of almost 11,000 articles prior to 2012, concluded that when compared to no intervention, technology-enhanced simulation training of health care professionals was consistent with large effects for knowledge, skills, and behavior and moderate effects for patient related outcomes. The authors also question the need for any further studies showing the benefit of simulation technology considering that only $4 \%$ of the studies failed to show an association when comparing no intervention to simulation intervention. They suggest that we focus on clarifying when and how to apply simulation most effectively and cost-efficiently.

The culture of MHE is gradually changing to a new one of accountability in quality improvement. In 2001, the IOM proposed six fundamental patient care aims to be learned by health care students: 1) safety, 2) effectiveness, 3) patient-centeredness, 4) timeliness, 5) efficiency, and 6) equitability. A premium needs to be placed on efficient team-oriented promoters of quality, safety, patient's preferences, prevention and wellness (IOM, 2001). In 2002, the American Board of Internal Medicine, the American College of Physicians, the American Society of Internal Medicine and the European Federation of Internal Medicine chartered a professionalism creed that states, “... improvement of quality of care, maintaining clinical competence, reduce medical errors, work with other professionals, increase patient safety, and optimize outcomes ...” (ABIM, 2002). Additionally, in 2004, the IOM reported the need to teach behavioral and social sciences to equip health care students to respond to patients as individuals and not just symptoms. The expected outcome was to build better therapeutic relationships and to be more patient-centered. At the University of South Florida, a project addressing these issues to surgical residents exposed to lectures, role model playing, and mentoring reduced medical errors (Brannick et al., 2009). The University of North Carolina uses the Team Strategies and Tools to Enhance Performance and Patient Safety (TeamSTEPPS) to prepare medical health care providers. TeamSTEPPS has resulted in physicians reporting 1) prevention in medical errors, 2) removal of the hierarchical inhibition to speak, 3) time-outs, 4) sign placement to protect patients, and e) utilization of team huddles before procedures (AHRQ, 2013). [Other centers are applying similar educational tools to address all of these areas.]

In the US, we have one of the highest ratios in the world of physicians/population $(25 / 10,000)$ trailing Europe and Russia, 30 s and lower 40 s per 10,000-population, respectively. Other parts of the world, like most of the sub-Sahara Africa countries, average about 0.5-1 physicians per 10,000-population (ChartBin, 2013). With such deficiencies in underdeveloped countries, medical and health educators must resort to preparing the health care force in the least expensive and most efficient manner. For example, can we teach an adult with an eighth-grade education to deliver anesthesia in an African country over the internet? Is that better than having no anesthesiologists, as is the case presently, in some of those countries? For circumstances like these, perhaps the future of health care education is global Massive Open Online Courses (MOOC) or a high-quality online educational content course available for the international health care community. These are not online lecture courses, but rather, an understanding, connecting, and exchanging of ideas through interaction with others via discussions that form the basis of the future of education in general (Faust, 2013). Skype is such an example today. Medical health education continues to advance through technology by the use of evolving digital computer innovations, which allow us to share in global knowledge. Both MOOCs and simulations will lead medical health education in the years ahead.

\section{The Future}

In concluding, health care delivery will change in the future. Continuously rising costs will be curtailed as the public demands make the profession accountable in quality improvement and safety. In order to do so, medical school educators need to change the curricula to emphasize the: 1) integration of patient care aims to become sensitive patient-centric and customerfocused rather than provider-centric; 2) introduction of competencies to self-evaluate, improve and develop lifelong learning and quality-improvement skills, be system aware, be evidencebased standardized medical practice, develop interdisciplinary professional teamwork and evaluate efficiency, quality and safety; 3) teaching of Comparative Effectiveness Research to deliver the best effective, efficient, safe benefit-to-cost health care; 4) decision-making attitudes; 5) formation of data bases to compare efficacy of disease/treatment results; 6) acknowledgement of accountability; 7) practice of human dynamics, such as, basic communications and teamwork skills, which coordinate care efficiently and proactively promoting wellness 
(Kumar, 2011); and 8) incorporation of simulation technology for quality and collaborative patient-centered care and global Massive Open Online Courses to facilitate Medical and Health Education world-wide.

\section{REFERENCES}

ABIM Foundation, American Board of Internal Medicine, ACP-ASIM Foundation, American College of Physicians-American Society of Internal Medicine, European Federation of Internal Medicine (2002). Medical professionalism in the new millennium: A physician charter. Annals of Internal Medicine, 136, 243-246. doi:10.7326/0003-4819-136-3-200202050-00012

Agency for Healthcare Research and Quality. Back Pain Patient Outcomes Assessment Team (BOAT). URL. http://www.ahrq.gov/clinic/medtep/backpain.htm http://www.acgme.org/acgmeweb/

Agency for Health Care Research Quality. TeamSTEPPS: National Implementation. URL. http://teamstepps.ahrq.gov/index.htm http://chartsbin.com/view/gcu

Brannick, M. T., Fabri, P. J., et al. (2009). Evaluation of an error-reduction training program for surgical residents. Academic Medicine, 84, 1809-1814. doi:10.1097/ACM.0b013e3181bf36b0

Cook, D. A., Hatala, R., Brydges, R., Zendejas, B., Szostek, J. H., Wang, A. T., Erwin, P. J., \& Hamstra, S. J. (2011). Technology-enhanced simulation for health professions education: A systematic review and meta-analysis. Journal of the American Medical Association, 306, 978-988. doi:10.1001/jama.2011.1234

Cooke, M., Irby, D. M., Sullivan, W., \& Ludmerer, K. M. (2006). American medical education 100 years after the Flexner report. New England Journal of Medicine, 355, 1339-1344. http://content.nejm.org/cgi/reprint/355/13/1339.pdf
doi:10.1056/NEJMra055445

Faust, D. (2013) The future of education. The view from mast hall. Harvard Magazine, 63.

Flexner, A. (1910). Medical education in the United States and Canada: A report to the Carnegie Foundation for the Advancement of Teaching. New York: Bulletin Number Four.

Gurusamy, K., Aggarwal, R., Palanivelu, L., \& Davidson, B. R. (2008). Systematic review of randomized controlled trials on the effectiveness of virtual reality training for laparoscopic surgery. British Journal of Surgery, 95, 1088-1097. www.bjs.co.uk doi:10.1002/bjs.6344

Institute of Medicine (IOM) (2009). Initial national priorities for comparative effectiveness research. Washington, DC: The National Academies Press. URL. http://www.iom.edu/cerpriorities

Institute of Medicine (IOM) (2001). Crossing the quality chasm: A New health system for the 21st Century. Washington, DC: The National Academies Press.

Kumar, S., \& Nash, D. B. (2011) Demand better: Revive our BROKEN healthcare system (p. 187). Bozeman, MT: Second River Healthcare Press.

Ma, I. W., Brindle, M. E., Ronksley, P. E., Lorenzetti, D. L., Sauve, R. S., \& Ghali, W. A. (2011). Use of simulation-based education to improve outcomes of central venous catheterization: A systematic review and meta-analysis. Academic Medicine, 86, 1137-1147. doi:10.1097/ACM.0b013e318226a204

McFlynn, E. A., Asch, S. M., et al. (2003). The quality of healthcare delivered to adults in the United States. The New England Journal of Medicine, 348, 2635-2645. doi:10.1056/NEJMsa022615

Ramsey, P. G., \& Miller, E. D. (2009). A single mission for academic medicine: Improving health. Journal of the American Medical Association, 301, 1475-1576.

http://jama.ama-assn.org/cgi/content/full/310/14/1475 doi:10.1001/jama.2009.472 